\title{
Matrine Attenuates COX-2 and ICAM-1 Expressions in Human Lung Epithelial Cells and Prevents Acute Lung Injury in LPS-Induced Mice
}

\author{
Chian-Jiun Liou, ${ }^{1,2}$ You-Rong Lai, ${ }^{3}$ Ya-Ling Chen, ${ }^{3}$ Yi-Hsien Chang, ${ }^{3}$ \\ Zih-Ying $\mathrm{Li}^{2}{ }^{2}$ and Wen-Chung Huang ${ }^{2,4,5}$ \\ ${ }^{1}$ Department of Nursing, Chang Gung University of Science and Technology, No. 261 Wenhua 1st Road, Guishan District, \\ Taoyuan City 33303, Taiwan \\ ${ }^{2}$ Chang Gung Memorial Hospital at Linkou, Guishan District, Taoyuan City 33303, Taiwan \\ ${ }^{3}$ Department of Nutrition and Health Sciences, Chang Gung University of Science and Technology, No. 261 Wenhua 1st Road, \\ Guishan District, Taoyuan City 33303, Taiwan \\ ${ }^{4}$ Research Center for Industry of Human Ecology, Chang Gung University of Science and Technology, No. 261 Wenhua 1st Road, \\ Guishan District, Taoyuan City 33303, Taiwan \\ ${ }^{5}$ Graduate Institute of Health Industry Technology, Chang Gung University of Science Taiwan and Technology, \\ No. 261 Wenhua 1st Road, Guishan District, Taoyuan City 33303, Taiwan
}

Correspondence should be addressed to Wen-Chung Huang; wchuang@gw.cgust.edu.tw

Received 8 September 2015; Revised 8 November 2015; Accepted 10 November 2015

Academic Editor: Mirella Giovarelli

Copyright (c) 2016 Chian-Jiun Liou et al. This is an open access article distributed under the Creative Commons Attribution License, which permits unrestricted use, distribution, and reproduction in any medium, provided the original work is properly cited.

\begin{abstract}
Matrine is isolated from Sophora flavescens and shows anti-inflammatory effects in macrophages. Here we evaluated matrine's suppressive effects on cyclooxygenase 2 (COX-2) and intercellular adhesion molecule-1 (ICAM-1) expressions in lipopolysaccharide(LPS-) stimulated human lung epithelial A549 cells. Additionally, BALB/c mice were given various matrine doses by intraperitoneal injection, and then lung injury was induced via intratracheal instillation of LPS. In LPS-stimulated A549 cells, matrine inhibited the productions of interleukin-8 (IL-8), monocyte chemotactic protein-1, and IL-6 and decreased COX-2 expression. Matrine treatment also decreased ICAM-1 protein expression and suppressed the adhesion of neutrophil-like cells to inflammatory A549 cells. In vitro results demonstrated that matrine significantly inhibited mitogen-activated protein kinase phosphorylation and decreased nuclear transcription factor kappa-B subunit p65 protein translocation into the nucleus. In vivo data indicated that matrine significantly inhibited neutrophil infiltration and suppressed productions of tumor necrosis factor- $\alpha$ and IL-6 in mouse bronchoalveolar lavage fluid and serum. Analysis of lung tissue showed that matrine decreased the gene expression of proinflammatory cytokines, chemokines, COX-2, and ICAM-1. Our findings suggest that matrine improved lung injury in mice and decreased the inflammatory response in human lung epithelial cells.
\end{abstract}

\section{Introduction}

Acute lung injury (ALI) is characterized by atelectasis of lung airspaces, reducing the total lung capacity [1]. In ALI cases, the lung tissue releases large amounts of inflammatory cytokines, chemokines, and inflammatory media, such as nitric oxide and cyclooxygenase 2 (COX-2) [2]. ALI also causes lung cells to secrete more proteases, leading to alveolar cell damage and fluid accumulation in alveoli, causing edema in the lung tissue [3]. Alveolar damage results in increased vascular permeability of blood vessels and neutrophil infiltration in the lung tissue, further exacerbating lung inflammation and pulmonary edema and potentially causing respiratory failure and death [4].

ALI commonly occurs as an early symptom of sepsis or bacterial infection of the respiratory tract [2]. Gramnegative bacterial invasion of the lungs can cause bacterial pneumonia and ALI [5]. Lipopolysaccharide (LPS) is a cell 
wall component of Gram-negative bacteria and can induce an innate immunity response, activating immune cells to combat microbial infection [6]. Thus, LPS is widely used to induce acute lung inflammation in animal models. Activated macrophages and lung epithelial cells reportedly release proinflammatory cytokines and chemokines, aggravating ALI progression. Prior studies have used lung epithelial cells to evaluate the anti-inflammatory responses of drugs or natural compounds during LPS-induced inflammatory response $[7,8]$.

In China and Taiwan, the root of Sophora flavescens (Leguminosae) is used to treat fever, jaundice, urinary tract infections, and pyogenic infections [9]. Matrine is isolated from S. flavescens and can reportedly attenuate cerebral ischemic injury in mice and induce apoptosis of chronic myeloid leukemia cells, osteosarcoma cells, and cholangiocarcinoma cells $[9,10]$. Zhang et al. previously demonstrated that matrine suppressed proinflammatory cytokine production in LPS-stimulated mouse macrophages [11]. Previously, our group also found that matrine could improve eosinophil infiltration, airway hyperresponsiveness, and Th2-associated cytokine production in asthmatic mice [12]. However, the mechanisms of matrine's anti-inflammatory activity in lung epithelial cells are largely unclear.

In the present study, we investigated whether matrine reduced inflammatory responses and production of intercellular adhesion molecule-1 (ICAM-1) in lung epithelial cells. We also examined whether matrine protected and prevented acute lung injury in LPS-induced mice.

\section{Materials and Methods}

2.1. Matrine and Cell Culture. Matrine ( $\geq 99 \%$ by HPLC) was purchased from Sigma-Aldrich (St. Louis, MO, USA) and was dissolved in normal saline as previously described [12]. The human lung epithelial cell line A549 was purchased from the Bioresource Collection and Research Center (BCRC, Taiwan). A549 cells were cultured in DMEM medium (Invitrogen-Gibco, Paisley, Scotland) containing $2 \mathrm{mM}$ glutamine, $100 \mathrm{U} / \mathrm{mL}$ penicillin and streptomycin, and $10 \%$ fetal bovine serum (Biological Industries, Haemek, Israel). Cells were incubated at $37^{\circ} \mathrm{C}$ in $5 \% \mathrm{CO}_{2}$ humidified air and were subcultured twice each week.

2.2. Cell Viability Assay. Cell viability was assayed using 3(4,5-dimethylthiazol-2-yl)-2,5-diphenyltetrazolium bromide (MTT; Sigma) as previously described [13]. In 96-well culture plates, A549 cells were treated with various matrine concentrations for $24 \mathrm{~h}$. The plates were then washed, MTT solution was added, and the plates were incubated at $37^{\circ} \mathrm{C}$ for $4 \mathrm{~h}$. Formazan crystals were dissolved in isopropanol, and cell viability was spectrophotometrically measured at $570 \mathrm{~nm}$ with a microplate reader (Multiskan FC; Thermo, Waltham, MA, USA).

2.3. Animals. Female BALB/c mice were purchased from the National Laboratory Animal Center in Taiwan. Mice were maintained in animal housing with a thermostat and central air conditioning. The care and housing of the mice were approved by the Laboratory Animal Care Committee of Chang Gung University of Science and Technology (IACUC approval number: 2014-007).

2.4. Acute Lung Injury and Drug Treatment. The mice were randomly divided into four groups of 10 mice each: normal control mice ( $\mathrm{N}$ group), the LPS group, $10 \mathrm{mg} / \mathrm{kg}$ matrine plus LPS (M10 group), and $20 \mathrm{mg} / \mathrm{kg}$ matrine plus LPS (M20 group). On days 1-7 of the experiment, mice were intraperitoneally injected with matrine. On day 8, the mice were anesthetized with isoflurane (Aesica, Kent, UK) and received intratracheal injection of $50 \mu \mathrm{L}$ LPS $(1 \mu \mathrm{g} / \mathrm{mL})$ or normal saline. Four hours after LPS administration, the mice were sacrificed and we collected samples of serum, bronchoalveolar lavage fluid (BALF), and lung tissue.

2.5. Bronchoalveolar Lavage Fluid and Cell Count. BALF was collected as described previously [14]. Briefly, the mouse trachea was intubated and the lungs were flushed with $1 \mathrm{~mL}$ normal saline. To determine the neutrophil cell count in BALF, the cells were stained with Liu stain solution (Polysciences, Inc., Taipei, Taiwan). The supernatants were also measured for cytokine and chemokine productions.

2.6. Histological Analysis of Lung Tissue. Lung tissues were fixed in $10 \%$ formalin, embedded in paraffin, and cut into $6 \mu \mathrm{m}$ sections. The slides were stained with hematoxylin and eosin (HE). The neutrophil infiltration assay was performed as described previously [15].

2.7. Serum Collection. Following anesthetization, serum was collected from the orbital vascular plexus. Serum samples were centrifuged at $6000 \mathrm{rpm}$ for $5 \mathrm{~min}$ as previously described [16], followed by storage at $-80^{\circ} \mathrm{C}$ until use.

2.8. ELISA for Cytokine and Chemokine Production. In an in vitro experiment, A549 cells were pretreated with matrine $(100-400 \mu \mathrm{M})$ for $1 \mathrm{~h}$ in 24 -well plates and then they were stimulated with LPS $(1 \mu \mathrm{g} / \mathrm{mL})$ and cultured for $24 \mathrm{~h}$. We then used specific ELISA kits (R\&D Systems, Minneapolis, MN, USA) to assay IL-8, IL-6, monocyte chemotactic protein1 (MCP-1), CCL5, and ICAM-1 production. Optical density (OD) was spectrophotometrically measured at $450 \mathrm{~nm}$ using a microplate reader (Multiskan FC, Thermo). In our in vivo study, we also used ELISA to measure cytokines and chemokines in serum and BALF.

2.9. RNA Isolation and Real-Time PCR for Gene Expression. Total RNA was extracted from lung tissue using TRIzol reagent (Life Technologies, Carlsbad, CA, USA). From this RNA, we synthesized cDNA using a cDNA synthesis kit (Life Technologies). We then used a real-time PCR system kit (BioRad Laboratories, Hercules, CA, USA) with a spectrofluorometric thermal cycler (iCycler; Bio-Rad) to detect cDNA gene expression. Table 1 presents the specific gene primers that were used. 
TABLE 1: Primers used in real-time PCR analyses of mRNA expression.

\begin{tabular}{|c|c|c|c|c|}
\hline Gene & Primers & $\left(5^{\prime}-3^{\prime}\right.$ sequence $)$ & GenBank accession number & Product size (bp) \\
\hline IL- $1 \beta$ & $\begin{array}{l}\text { Forward } \\
\text { Reverse }\end{array}$ & $\begin{array}{l}\text { CACTACAGGCTCCGAGATGA } \\
\text { CGTTGCTTGGTTCTCCTTGT }\end{array}$ & NM_008361 & 143 \\
\hline IL-4 & $\begin{array}{l}\text { Forward } \\
\text { Reverse }\end{array}$ & $\begin{array}{l}\text { TCCGTGCTTGAAGAAGAACTC } \\
\text { GTGATGTGGACTTGGACTCATT }\end{array}$ & NM_021283.2 & 116 \\
\hline IL-6 & $\begin{array}{l}\text { Forward } \\
\text { Reverse }\end{array}$ & $\begin{array}{l}\text { AGGACCAAGACCATCCAATTCA } \\
\text { GCTTAGGCATAACGCACTAGG }\end{array}$ & NM_031168.1 & 97 \\
\hline IL-13 & $\begin{array}{l}\text { Forward } \\
\text { Reverse }\end{array}$ & $\begin{array}{l}\text { GCTCCAGCATTGAAGCAGTG } \\
\text { CGTGGCAGACAGGAGTGTT }\end{array}$ & NM_008355.3 & 141 \\
\hline TNF- $\alpha$ & $\begin{array}{l}\text { Forward } \\
\text { Reverse }\end{array}$ & $\begin{array}{l}\text { GCACCACCATCAAGGACTC } \\
\text { AGGCAACCTGACCACTCTC }\end{array}$ & NM_013693 & 96 \\
\hline MCP-1 & $\begin{array}{l}\text { Forward } \\
\text { Reverse }\end{array}$ & $\begin{array}{l}\text { TTCCACAACCACCTCAAGCA } \\
\text { TTAAGGCATCACAGTCCGAGTC }\end{array}$ & NM_011333 & 80 \\
\hline CCL5 & $\begin{array}{l}\text { Forward } \\
\text { Reverse }\end{array}$ & $\begin{array}{l}\text { CGAAGGAACCGCCAAGTGT } \\
\text { AGGACTAGAGCAAGCAATGAC }\end{array}$ & NM_013653.3 & 139 \\
\hline CCL11 & $\begin{array}{l}\text { Forward } \\
\text { Reverse }\end{array}$ & $\begin{array}{l}\text { GGCTTCATGTAGTTCCAGAT } \\
\text { CCATTGTGTTCCTCAATAATCC }\end{array}$ & NM_011330.3 & 145 \\
\hline CCL24 & $\begin{array}{l}\text { Forward } \\
\text { Reverse }\end{array}$ & $\begin{array}{l}\text { AGGCAGTGAGAACCAAGT } \\
\text { GCGTCAATACCTATGTCCAA }\end{array}$ & NM_019577.4 & 102 \\
\hline iNOS & $\begin{array}{l}\text { Forward } \\
\text { Reverse }\end{array}$ & $\begin{array}{l}\text { TTCCACAACCACCTCAAGCA } \\
\text { TTAAGGCATCACAGTCCGAGTC }\end{array}$ & NM_010927 & 83 \\
\hline COX-2 & $\begin{array}{l}\text { Forward } \\
\text { Reverse }\end{array}$ & $\begin{array}{l}\text { ACCAGCAGTTCCAGTATCAGA } \\
\text { CAGGAGGATGGAGTTGTTGTAG }\end{array}$ & NM_011198 & 143 \\
\hline ICAM-1 & $\begin{array}{l}\text { Forward } \\
\text { Reverse }\end{array}$ & $\begin{array}{l}\text { AACAGAATGGTAGACAGCAT } \\
\text { TCCACCGAGTCCTCTTAG }\end{array}$ & NM_010493.2 & 113 \\
\hline$\beta$-actin & $\begin{array}{l}\text { Forward } \\
\text { Reverse }\end{array}$ & $\begin{array}{l}\text { AAGACCTCTATGCCAACACAGT } \\
\text { AGCCAGAGCAGTAATCTCCTTC }\end{array}$ & NM_007393.3 & 92 \\
\hline
\end{tabular}

2.10. Cell-Cell Adhesion Assay. A549 cells were treated with matrine and incubated with LPS $(1 \mu \mathrm{g} / \mathrm{mL})$ for $24 \mathrm{~h}$. Then, neutrophil-like HL-60 cells were treated with calcein AM solution (Sigma) and cocultured with A549 cells for $1 \mathrm{~h}$. We observed the adhesion of HL-60 cells to A549 using fluorescence microscopy (Olympus, Tokyo, Japan).

2.11. Preparation of Total and Nuclear Proteins. Following treatment with matrine for $1 \mathrm{~h}$, A549 cells were stimulated with LPS $(1 \mu \mathrm{g} / \mathrm{mL})$ for $30 \mathrm{~min}$ to detect protein phosphorylation or for $24 \mathrm{~h}$ to evaluate total protein expressions. Proteins were extracted using protein lysis buffer containing protease and phosphatase inhibitors (Sigma). Nuclear proteins were extracted using NE-PER nuclear and cytoplasmic extraction reagent kits (Pierce, Rockford, IL, USA). All proteins were quantified using the BCA protein assay kit (Pierce).

2.12. Western Immunoblot Analysis. Equal amounts of protein were separated on $10 \%$ SDS polyacrylamide gels and then transferred to polyvinylidene fluoride (PVDF) membranes (Millipore, Billerica, MA, USA). The PVDF membranes were incubated overnight at $4^{\circ} \mathrm{C}$ with primary antibodies, including $\mathrm{COX}-2, \mathrm{I} \kappa \mathrm{B}-\alpha$, phosphorylated-I $\kappa \mathrm{B}-\alpha$, lamin B1, p65, phosphorylated-I $\kappa$ B- $\alpha$ (Santa Cruz, CA, USA), ERK1/2, p38, JNK, phosphorylated-ERK1/2, phosphorylatedp38, phosphorylated-JNK (Millipore), ICAM-1, and $\beta$-actin (Sigma). After the overnight incubation, the membrane was washed with TBST buffer $(150 \mathrm{mM} \mathrm{NaCl} ; 10 \mathrm{mM}$ Tris, $\mathrm{pH}$ 8.0; and 0.1\% Tween 20) and incubated with HRP-conjugated secondary antibodies for $1 \mathrm{~h}$. Finally, the membranes were washed and processed with Luminol/Enhancer Solution (Millipore) for detection and quantification of the specific protein using the BioSpectrum 600 system (UVP, Upland, CA, USA).

2.13. Transfection and Luciferase Assays. Transfected $\mathrm{pNF} \kappa \mathrm{B}-$ Luc plasmid evaluated NF- $\kappa$ B activity as previously described [13]. Briefly, A549 cells were transfected with pNFkB-Luc plasmid (Stratagene, California, USA) and cells were pretreated with matrine for $1 \mathrm{~h}$ and were stimulated with LPS for $4 \mathrm{~h}$. The luciferase activity was assayed using a Multi-Mode Microplate Reader (BioTek Synergy HT, Bedfordshire, United Kingdom).

2.14. Statistical Analysis. All data were analyzed using oneway analysis of variance (ANOVA), followed by TukeyKramer method for multiple comparisons. Values are expressed as mean \pm SEM. A $P$ value of $<0.05$ was considered to indicate a statistically significant difference.

\section{Results}

3.1. Effects of Matrine on Inflammatory Response in Activated A549 Cells. At doses of $\leq 400 \mu \mathrm{M}$, matrine did not affect 


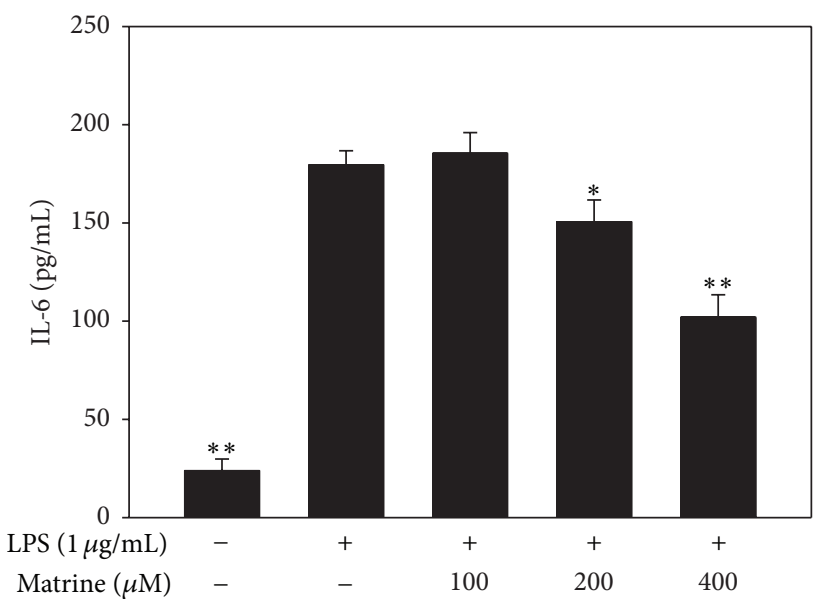

(a)

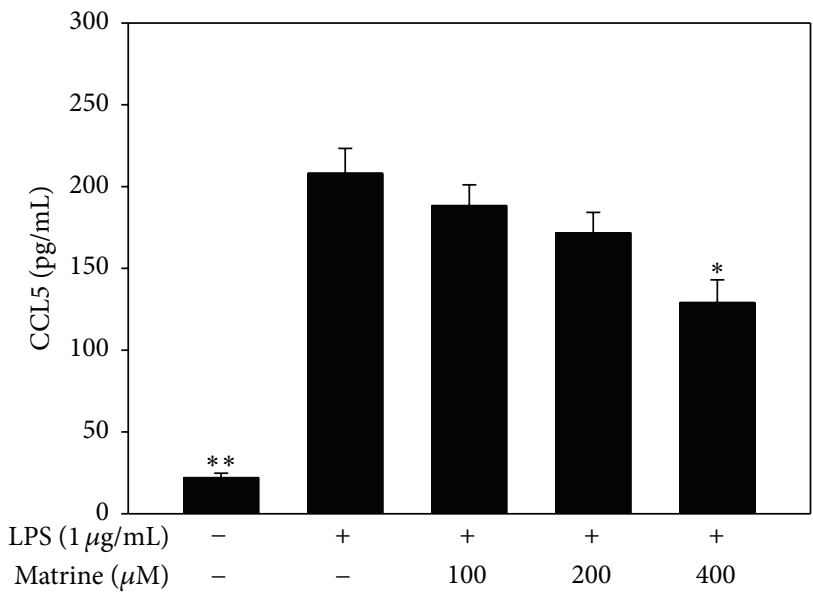

(c)

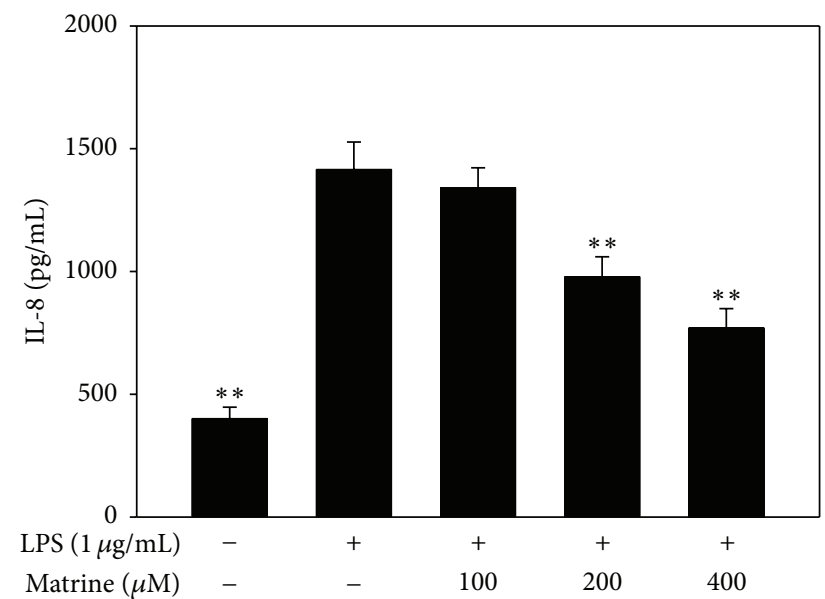

(b)

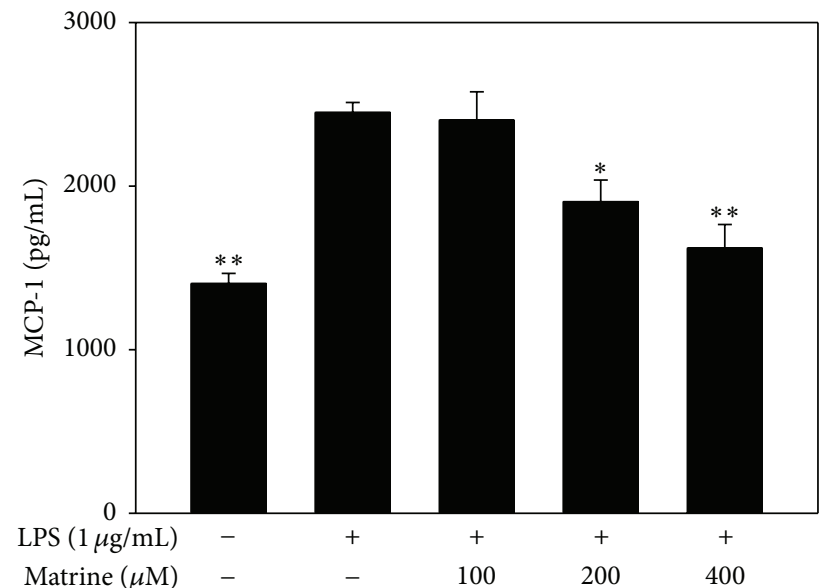

(d)

FIGURE 1: Matrine affects cytokine and chemokine productions in LPS-stimulated A549 cells. ELISA was used to measure the levels of IL-6 (a), IL-8 (b), CCL5 (c), and MCP-1 (d). All data are presented as mean \pm SEM. ${ }^{*} P<0.05$ compared with the LPS control group. ${ }^{* *} P<0.01$ compared with the LPS control group.

the viability of A549 cells (data not shown). Thus, matrine concentrations of $100-400 \mu \mathrm{M}$ were used in the in vitro experiments. First, we investigated how matrine modulated cytokine and chemokine production in LPS-stimulated A549 cells (Figure 1). We found that matrine significantly decreased IL-6 production in a concentration-dependent manner: IL-6 production with LPS alone, $179.4 \pm 7.9 \mathrm{pg} / \mathrm{mL}$; with $100 \mu \mathrm{M}$ matrine, $185.4 \pm 10.2 \mathrm{pg} / \mathrm{mL}(P=0.28$ versus LPS alone); $200 \mu \mathrm{M}$ matrine, $150.5 \pm 11.2 \mathrm{pg} / \mathrm{mL}(P<0.05$ versus LPS alone); $400 \mu \mathrm{M}$ matrine, $101.9 \pm 11.5 \mathrm{pg} / \mathrm{mL}(P<0.01$ versus LPS alone). Matrine also dose-dependently decreased the levels of IL-8, MCP-1, and CCL5 in LPS-stimulated A549 cells.

\subsection{Effects of Matrine on LPS-Induced COX-2 and ICAM-1} Protein Expressions. A549 cells were pretreated with matrine, followed by stimulation with LPS for $24 \mathrm{~h}$. Matrine pretreatment significantly suppressed COX-2 protein expression in a concentration-dependent manner compared with LPSstimulated A549 cells (Figure 2(a)). ELISA (Figure 2(b)) and Western blot analysis (Figure 2(a)) also showed that matrine significantly inhibited ICAM-1 expression: LPS alone, 215.9 \pm $24.3 \mathrm{pg} / \mathrm{mL}$; matrine $100 \mu \mathrm{M}, 192.9 \pm 10.3 \mathrm{pg} / \mathrm{mL}(P=0.12$ versus LPS alone); matrine $200 \mu \mathrm{M}, 163.8 \pm 18.4 \mathrm{pg} / \mathrm{mL}$ $(P<0.05$ versus LPS alone); matrine $400 \mu \mathrm{M}, 130.6 \pm$ $17.5 \mathrm{pg} / \mathrm{mL}(P<0.01$ versus LPS alone). Inflammatory lung epithelial cells express ICAM-1 to promote neutrophil adhesion [17]. Correspondingly, we also found that matrine treatment decreased the adherence of HL-60 cells to LPSstimulated A549 cells (Figure 2(c)).

\subsection{Effects of Matrine on LPS-Induced NF- $\kappa B$ Activation and} Phosphorylation of MAPK Pathways in Human Lung Epithelial Cells. Upon finding that matrine decreased productions of chemokines, proinflammatory cytokines, and COX-2 in LPS-stimulated A549 cells, we further investigated whether 


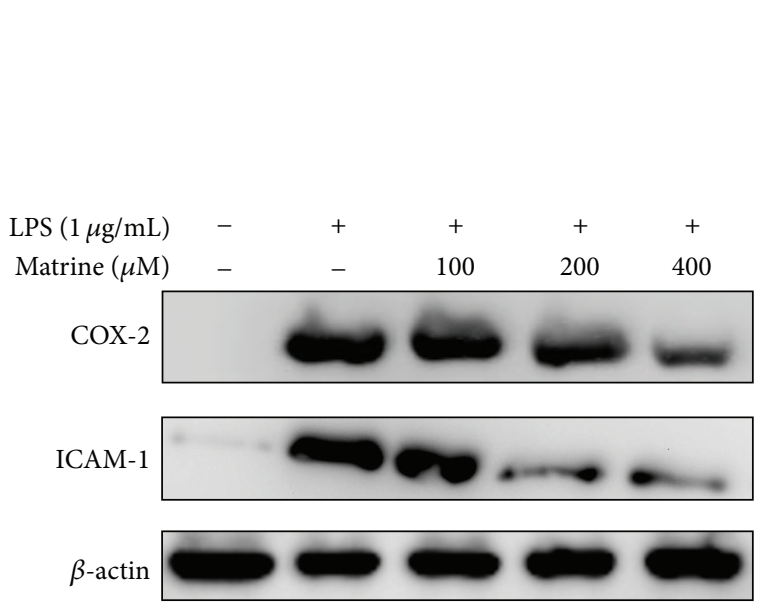

(a)

N

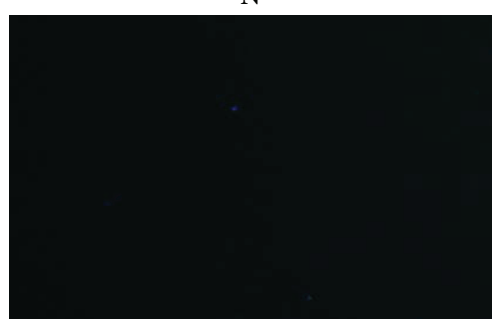

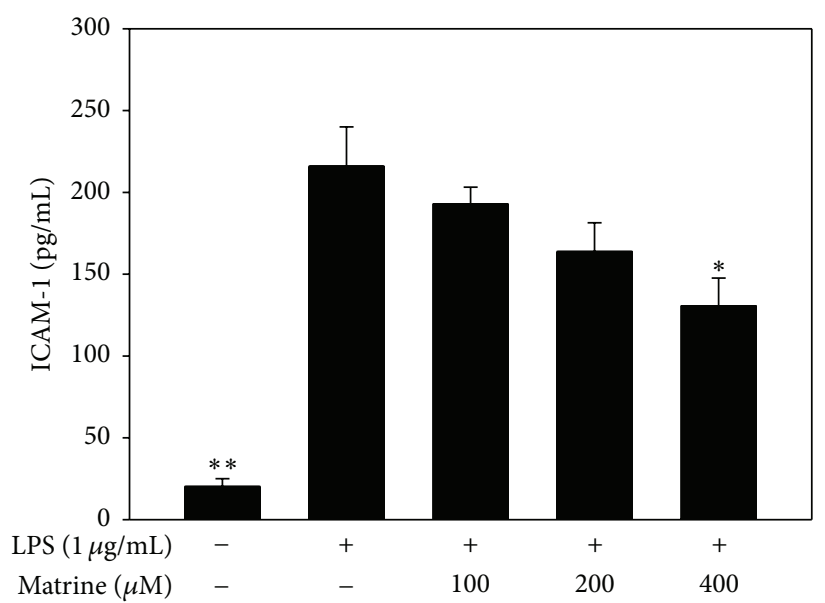

(b)

LPS
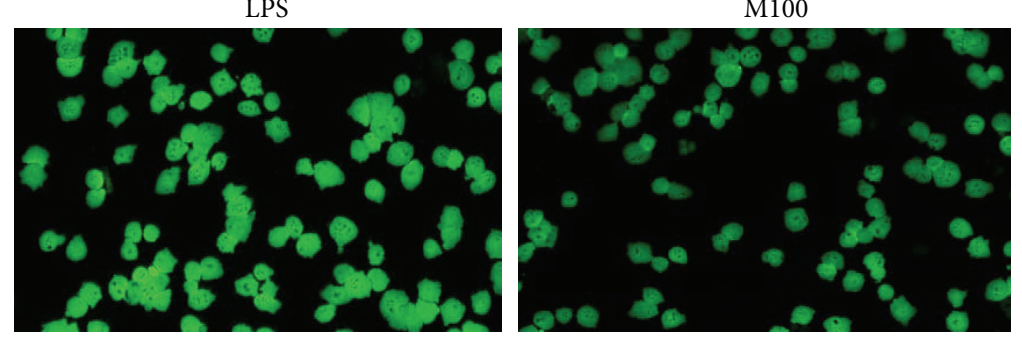

M400
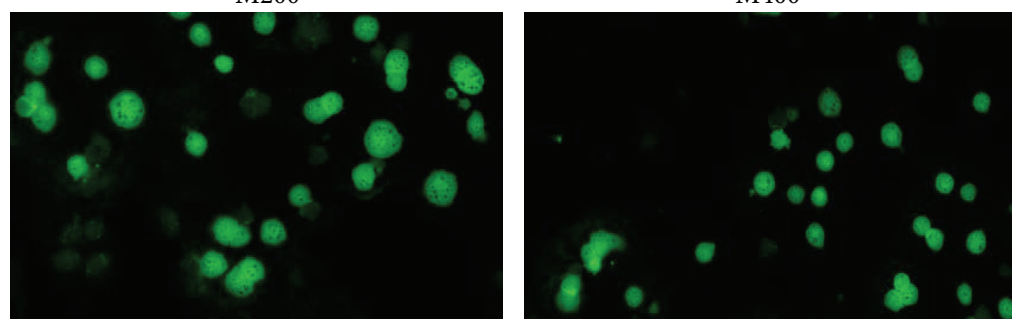

(c)

FIGURE 2: Matrine affects the LPS-induced productions of COX and ICAM-1 in A549 cells. COX-2 and ICAM-1 protein levels were detected using Western blots with $\beta$-actin expression as an internal control (a), and ICAM-1 levels were measured by ELISA (b). (c) Treatment with $100-400 \mu \mathrm{M}$ matrine $(\mathrm{M})$ inhibited the adherence of neutrophil-like HL-60 cells to active A549 cells. Data are presented as the mean \pm SEM. ${ }^{*} P<0.05$ compared to LPS alone.

matrine attenuated activation of the NF- $\kappa \mathrm{B}$ and MAPK pathways in these cells. In unstimulated cells, $\mathrm{I} \kappa \mathrm{B}$ holds the NF- $\kappa$ B complex (p65 and p50) in the cytoplasm, while LPS stimulation induces phosphorylation of $\mathrm{I} \kappa \mathrm{B}-\alpha$, increasing the release of p65 into the nucleus [18]. Here we found that matrine significantly inhibited $\mathrm{I} \kappa \mathrm{B}-\alpha$ phosphorylation and decreased I $\kappa$ B- $\alpha$ degradation, thus attenuating p65 translocation into the nucleus compared with that observed in LPSstimulated A549 cells (Figures 3(a) and 3(b)). NF- $\kappa$ B activity was evaluated using a promoter luciferase assay, and it was found that matrine could significantly decrease luciferase activity (Figure 3(c)). We also observed that matrine suppressed phosphorylation of ERK1/2, JNK, and p38 compared with LPS-stimulated A549 cells (Figure 4).
3.4. Matrine Inhibits Neutrophil Infiltration of LPS-Induced Lung Injury in Mice. After the sacrifice of mice, lung tissue was fixed with formalin and HE stained to analyze the distribution of neutrophils in lung sections. The LPS group showed greater neutrophil infiltration compared to the $\mathrm{N}$ group (Figure 5). Moreover, matrine treatment significantly suppressed neutrophil infiltration in the lung biopsy sections of mice.

3.5. Matrine Reduced the Neutrophil Count in BALF from LPSChallenged Mice. Evaluation of inflammatory cells in BALF revealed that matrine suppressed neutrophil infiltration in acute lung injury mice. Intraperitoneal injection of matrine in LPS-induced acute lung injury mice led to a significant 


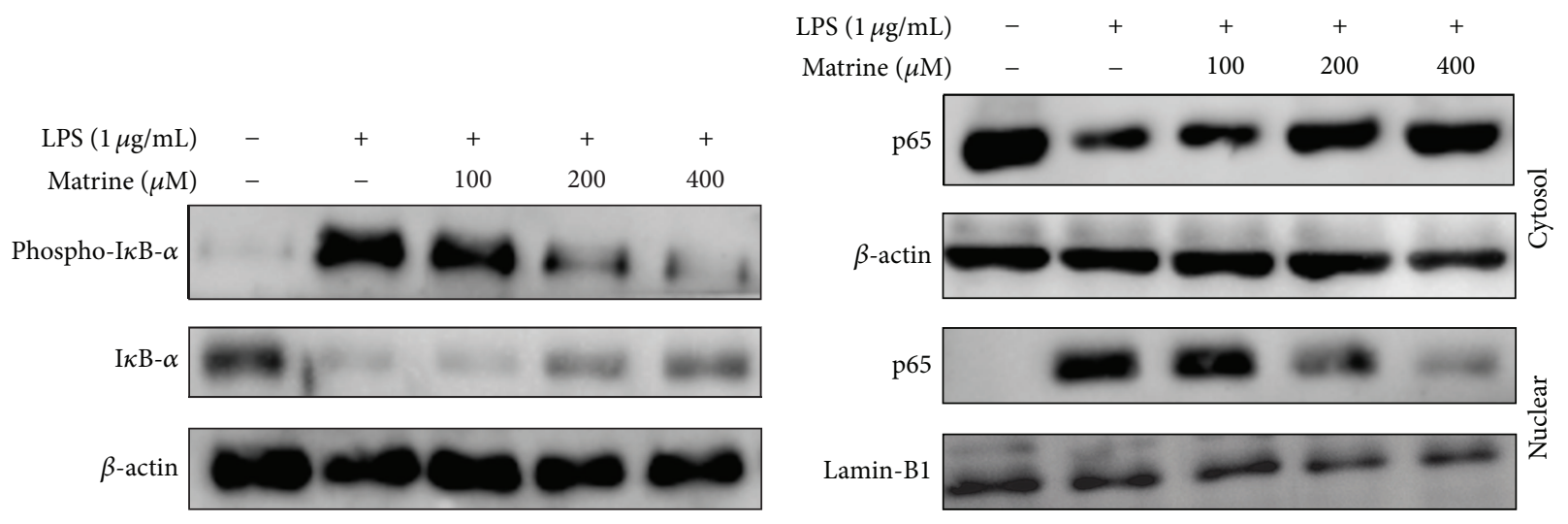

(a)

(b)

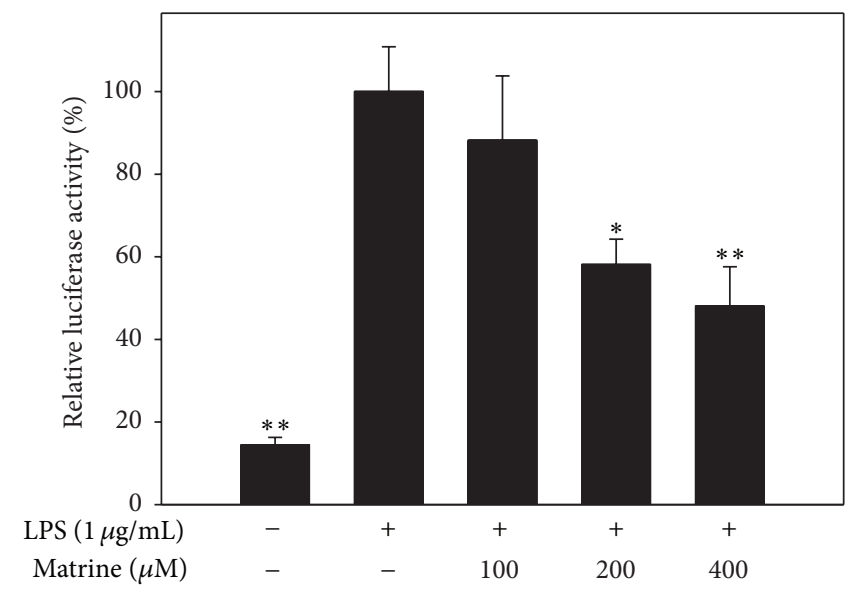

(c)

FIgURE 3: Matrine inhibits the nuclear translocation of NF- $\kappa$ B in A549 cells. (a) Effects of matrine on the LPS-induced phosphorylation of $\mathrm{I} \kappa \mathrm{B}-\alpha$, with total $\mathrm{I} \kappa \mathrm{B}-\alpha$ levels used as internal controls. (b) To assess the nuclear translocation of NF- $\kappa \mathrm{B}$, cells were pretreated with different matrine concentrations for $1 \mathrm{~h}$ and then incubated with LPS $(1 \mu \mathrm{g} / \mathrm{mL})$ for $1 \mathrm{~h}$. The internal controls were lamin B1 in the nucleus and $\beta$-actin in the cytosol. (c) Matrine suppressed luciferase activity by the NF- $\kappa$ B promoter assay. Three independent experiments were analyzed and compared with the LPS-treated control group. Data are presented as the mean \pm SEM. ${ }^{*} P<0.05$ compared to LPS alone.

decrease of neutrophils compared with the LPS group: LPS alone, $4.3 \times 10^{5} \pm 6.1 \times 10^{4}$ neutrophils/mL; M10, $2.7 \times 10^{5} \pm$ $7.1 \times 10^{4}$ neutrophils/mL $(P=0.08$ versus LPS alone); M20, $2.0 \times 10^{5} \pm 6.1 \times 10^{4}$ neutrophils $/ \mathrm{mL}(P<0.05$ versus LPS alone) (Figure 6(a)).

3.6. Effects of Matrine on Cytokine and Chemokine Levels in $B A L F$. Acute lung injury mice treated with matrine exhibited lower IL-6 levels: LPS alone, $347.8 \pm 97.6$ pg/mL; M10, $199.3 \pm$ $8.3 \mathrm{pg} / \mathrm{mL}(P<0.05$ versus LPS alone $) ;$ M20, $163.9 \pm$ $49.8 \mathrm{pg} / \mathrm{mL}(P<0.01$ versus LPS alone) (Figure 6(b)). Matrine treatment also reduced TNF- $\alpha$ levels in these mice: LPS alone, $556.3 \pm 111.9 \mathrm{pg} / \mathrm{mL} ; \mathrm{M} 10,441.0 \pm 71.1 \mathrm{pg} / \mathrm{mL}$ ( $P=0.11$ versus LPS alone); M20, $262.9 \pm 69.1 \mathrm{pg} / \mathrm{mL}(P<$ 0.05 versus LPS alone) (Figure $6(\mathrm{c})$ ). Using real-time PCR to evaluate gene expression, we found that matrine significantly decreased levels of IL- $1 \beta$, IL- 6 , TNF- $\alpha$, IL-13, MCP-1, and CCL5 in lung injury tissue (Figure 7). However, matrine did not suppress the gene expressions of IL-4, CCL11, or CCL24.
We further found that matrine inhibited the gene expressions of ICAM-1, iNOS, and COX-2 in lung injury tissue.

3.7. Effects of Matrine on Phosphorylation of NF- $\kappa B$ and MAPK Pathways in Lung Injury Tissue. Matrine significantly inhibited phosphorylation of p65 compared with that in LPS-stimulated lung injury tissue. Matrine also suppressed phosphorylation of ERK1/2, JNK, and p38 in the lung injury tissue (Figure 8).

3.8. Effects of Matrine on Cytokine Production in Serum. Serum analysis revealed significantly reduced IL- 6 production and TNF- $\alpha$ production in the M20 group compared to in the LPS group (Figure 9).

\section{Discussion}

Matrine is a major active component isolated from Sophora flavescens (Kushen), which reportedly shows many biological and medical properties, including improved inflammatory 


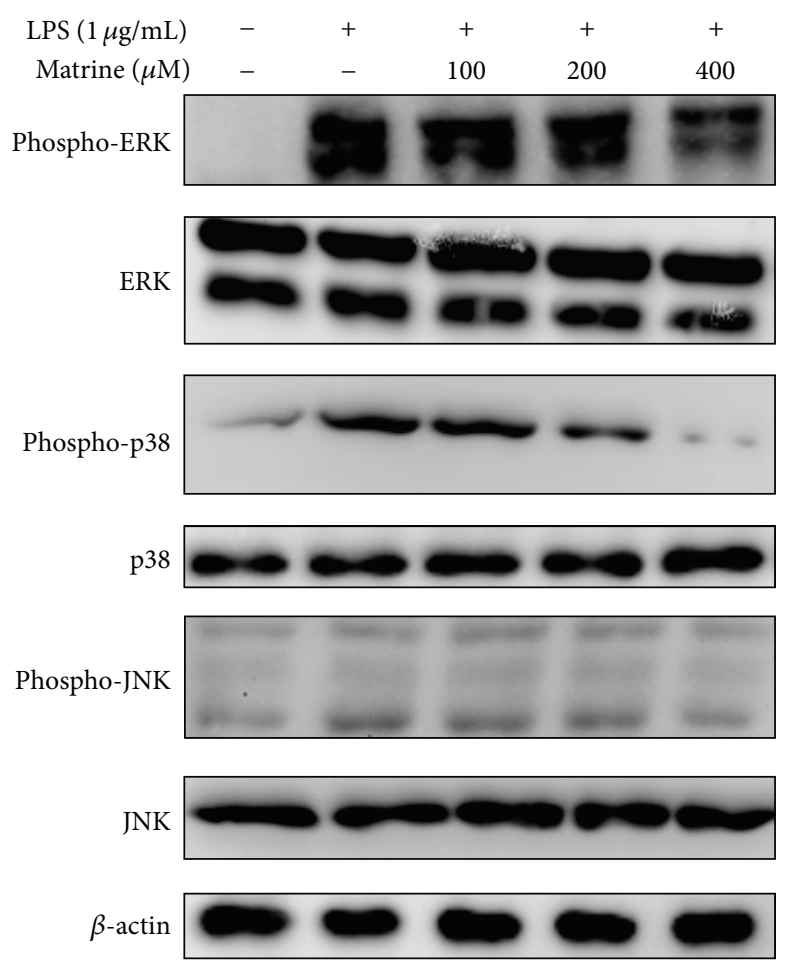

FIGURE 4: Matrine affects LPS-induced phosphorylation of MAPK pathway molecules. Western blots showed the effects of the indicated matrine concentrations on the phosphorylation of ERK (top two rows), p38 (middle two rows), and JNK (bottom two rows). Three independent experiments were analyzed and compared with the LPS-treated group.
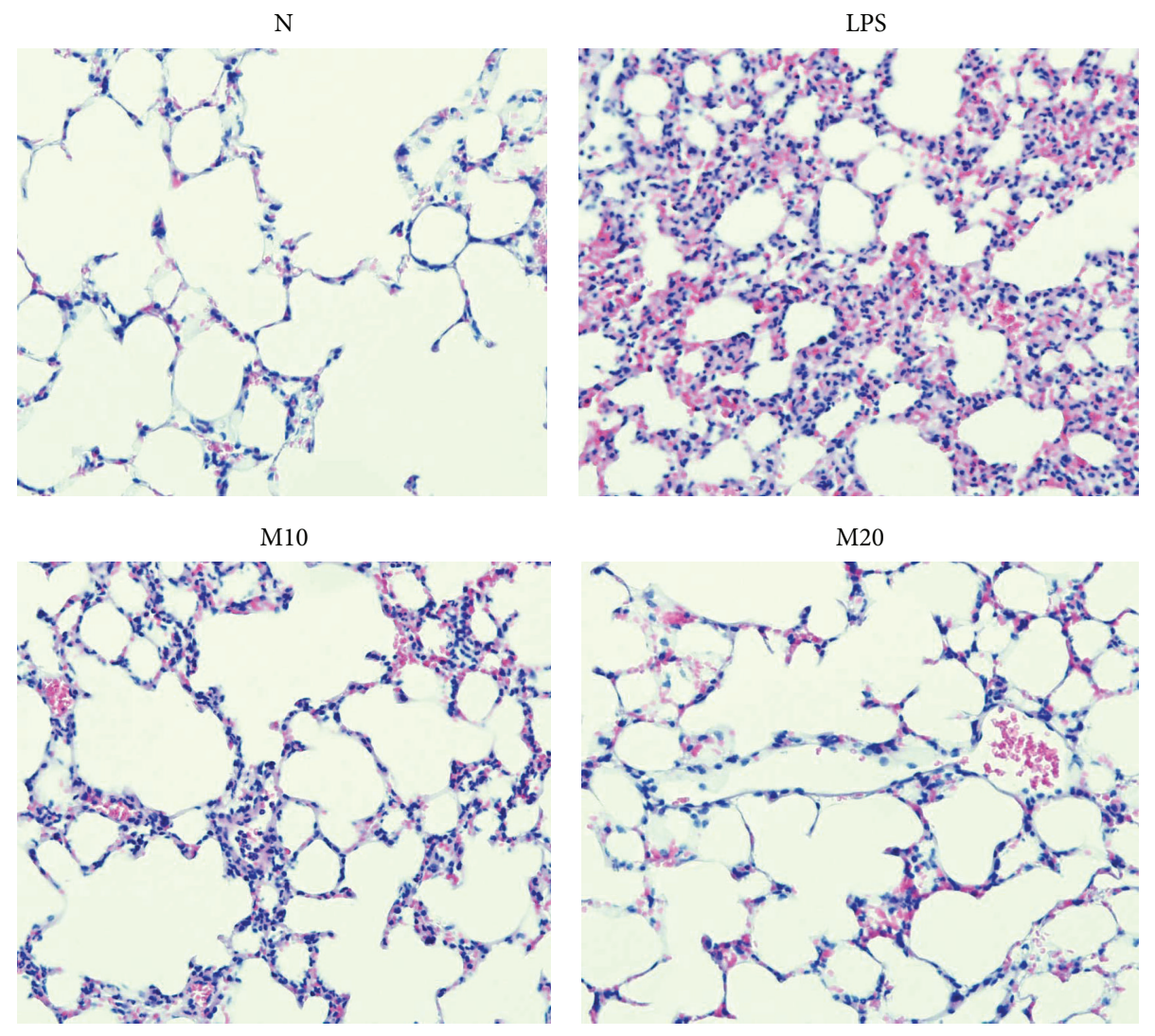

Figure 5: Matrine inhibits neutrophil infiltration. Hematoxylin and eosin staining was used for histological examination of airway inflammation in lung tissue (magnification, 400x). N group: normal control mice; LPS group: LPS treatment only; M10 group: $10 \mathrm{mg} / \mathrm{kg}$ matrine plus LPS; M20 group: $20 \mathrm{mg} / \mathrm{kg}$ matrine plus LPS. 


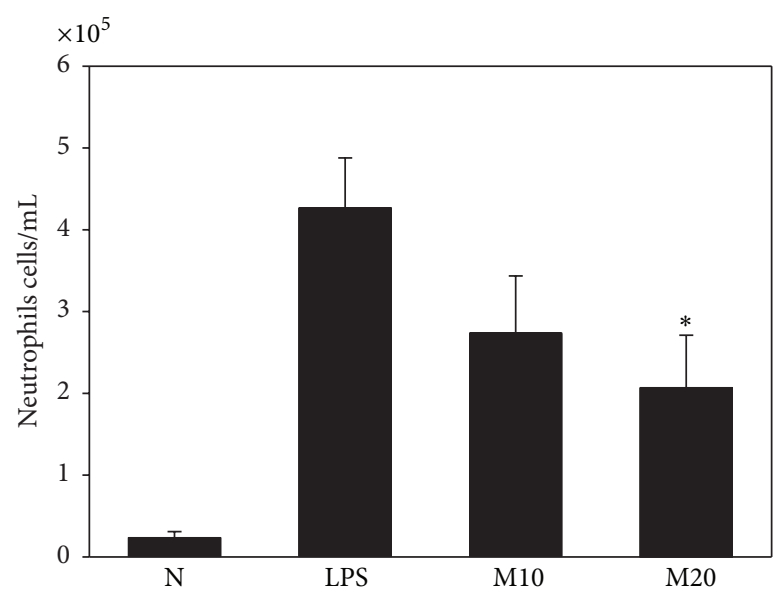

(a)

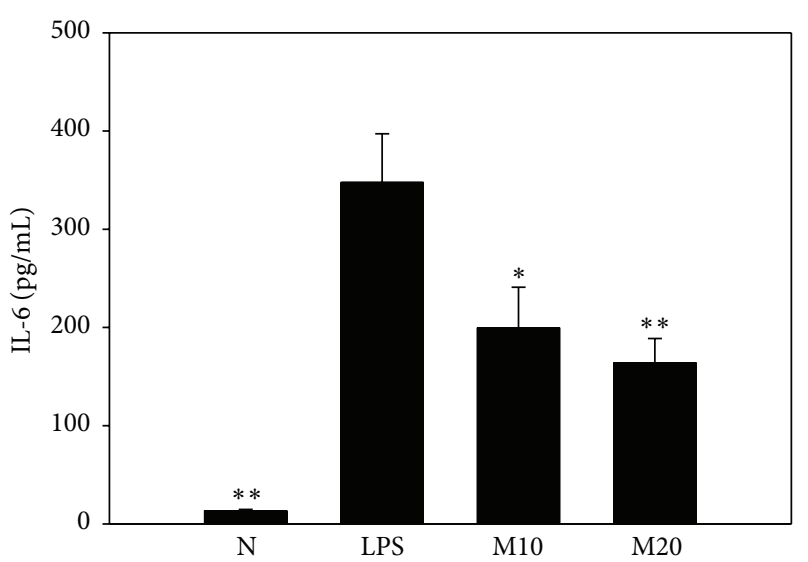

(b)

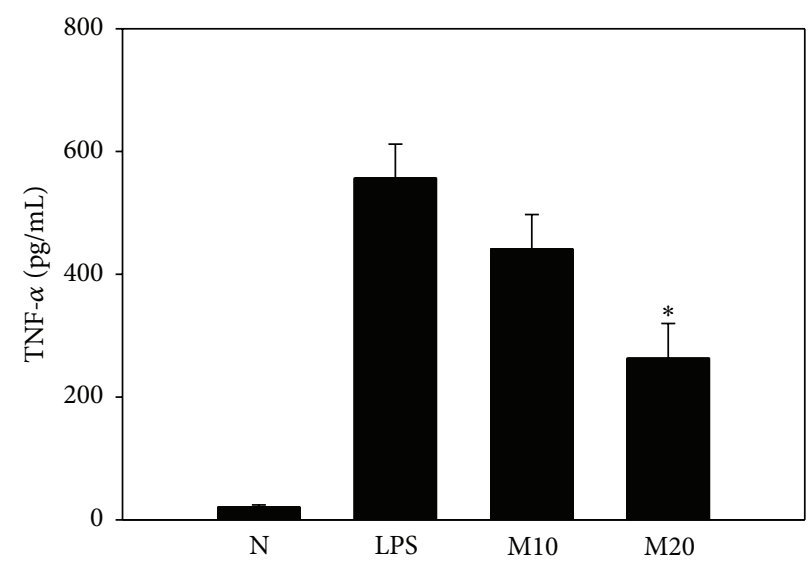

(c)

FIGURE 6: Matrine affects neutrophil counts and cytokine and chemokine levels in BALF. In the different treatment groups, we analyzed neutrophil cell counts (a), and the levels of IL-6 (b) and TNF- $\alpha$ (c) were measured by ELISA. N group: normal control mice; LPS group: LPS treatment only; M10 group: $10 \mathrm{mg} / \mathrm{kg}$ matrine plus LPS; M20 group: $20 \mathrm{mg} / \mathrm{kg}$ matrine plus LPS. All data are presented as mean \pm SEM. ${ }^{*} P<0.05$ compared with the LPS control group. ${ }^{* *} P<0.01$ compared with the LPS control group.

responses of the central nervous system, antitumor activities, and immunity-regulating effects $[10,19]$. We previously demonstrated that matrine suppresses eosinophil infiltration in lung tissue and improves airway hyperresponsiveness and suppresses tracheal goblet cell hyperplasia in asthmatic mice [12]. Moreover, Zhang et al. described lung histopathological changes and inflammatory response at $18 \mathrm{~h}$ after LPS injection in mice, reporting that matrine decreased myeloperoxidase and malondialdehyde activities and inhibited reactive oxygen species and oxidative stress in BALF [20].

In our present study, we investigated whether matrine improved the inflammatory response in acute lung injury mice at $4 \mathrm{~h}$ after LPS injection into the trachea and also examined inflammatory responses in LPS-stimulated human lung epithelial cells. Our results showed that matrine significantly suppressed COX-2 expression and productions of IL-6, IL-8, MCP-1, and CCL5 in LPS-stimulated A549 cells. Matrine treatment also suppressed ICAM-1 expressions and, correspondingly, reduced LPS-stimulated A549 cell adherence to neutrophils. Finally, matrine suppressed components of inflammatory signaling pathways, including the NF- $\kappa \mathrm{B}$ and MAPK pathways.

LPS is an important component of Gram-negative bacteria cell walls [21]. Upon infection with Gram-negative bacteria, LPS release leads to inflammation and fever symptoms, potentially causing severe acute or chronic organ congestion, edema, or even septic shock and death [22]. LPS stimulates $\mathrm{I} \kappa \mathrm{B}$ phosphorylation, emancipating NF- $\kappa \mathrm{B}$ (containing $\mathrm{p} 50$ and $\mathrm{p} 65$ ) to translocate into the nucleus. In the nucleus, p65 binds the promoters of inflammatory genes, leading to the expressions of proinflammatory cytokines, chemokines, COX-2, and ICAM-1 in LPS-stimulated A549 cells [21, 23]. MAPK pathways also modulate NF- $\kappa$ B activation to alter COX-2 and ICAM-1 expressions [24]. Our present experiments demonstrated that matrine significantly inhibited the secretion of proinflammatory cytokines and chemokines 


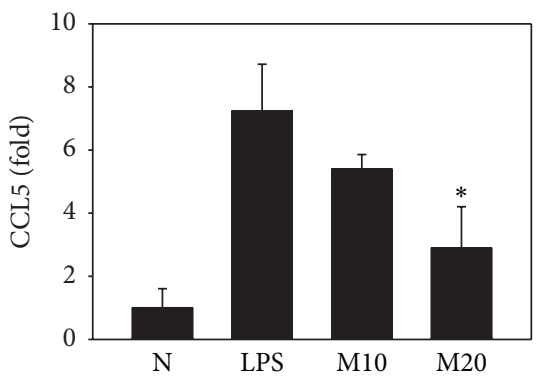

- CCL5

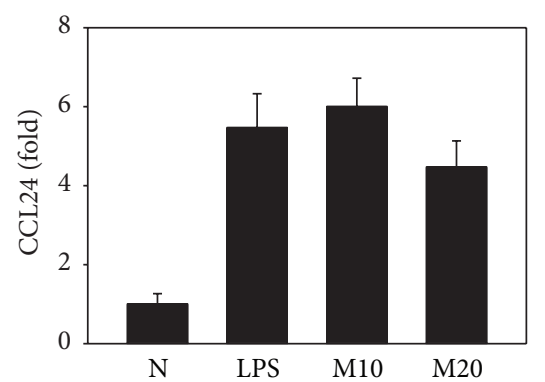

- CCL24

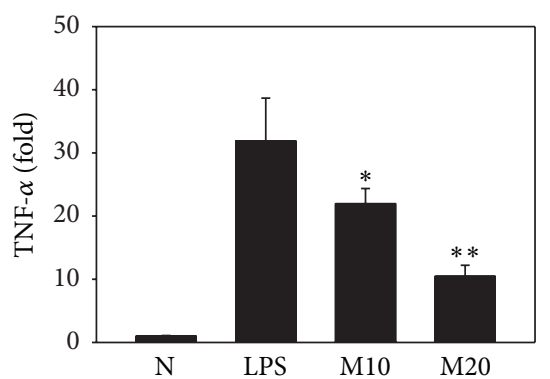

- TNF- $\alpha$

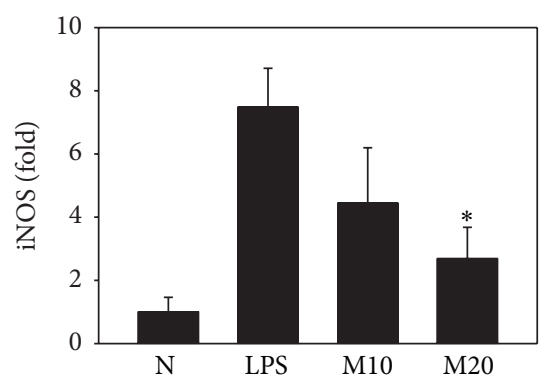

iNOS

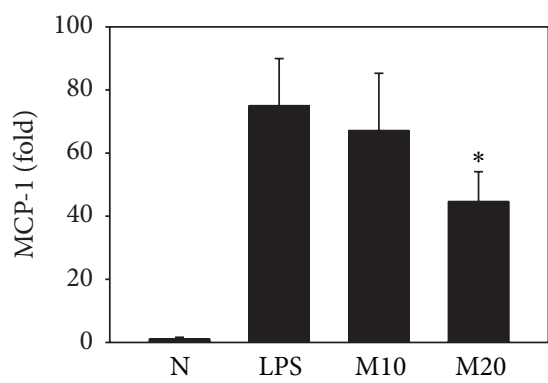

- MCP-1

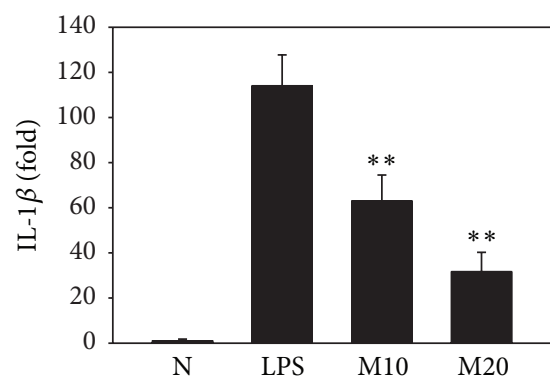

- IL-1 $\beta$

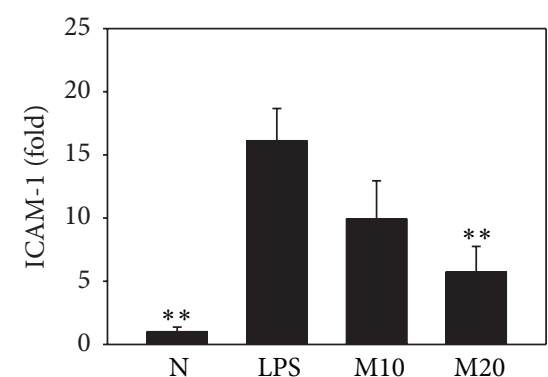

- ICAM-1

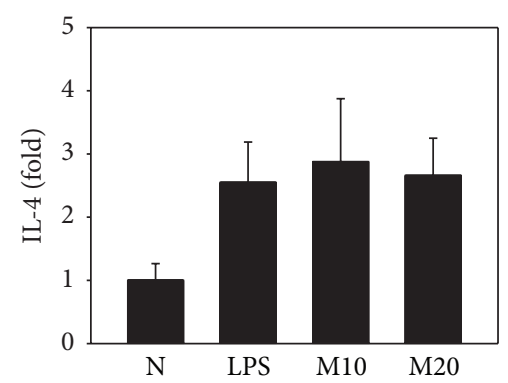

IL-4

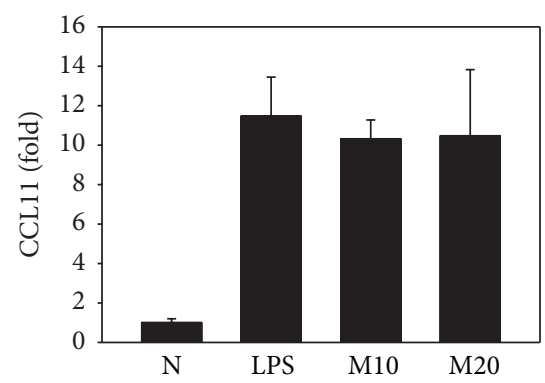

CCL11

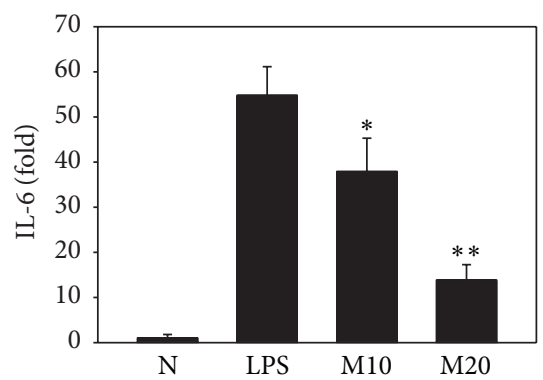

- IL-6

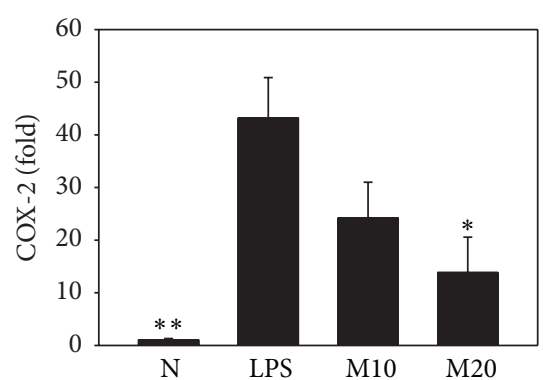

- COX-2

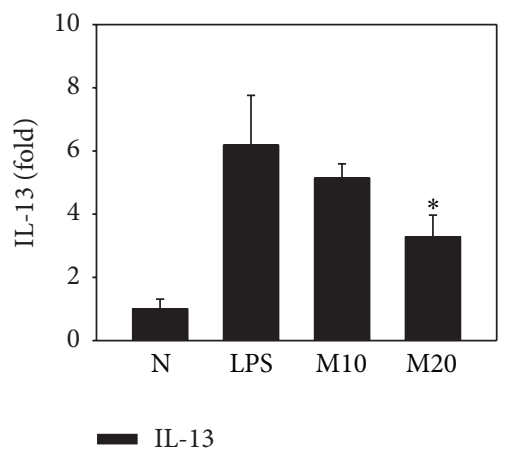

FiguRE 7: Matrine affects the expressions of cytokines, chemokines, and inflammatory mediators in the lung. Gene expressions were determined using real-time RT-PCR. Fold expression levels were measured relative to $\beta$-actin expression (internal control). Data are presented as mean \pm SEM. ${ }^{*} P<0.05$ compared with LPS control mice. ${ }^{* *} P<0.01$ compared with LPS control mice.

from LPS-induced A549 lung epithelial cells. This effect may have been because matrine inhibited MAPK and NF- $\kappa \mathrm{B}$ activation. These results suggest that matrine treatment could improve the inflammatory response in cases of lung bacterial infections.
Previously, Zhang et al. investigated the administration of matrine after $30 \mathrm{~min}$ of LPS stimulation and reported that matrine reduces lung inflammation and oxidation by inhibiting inflammatory signal pathways [20]. However, their protocol involved LPS injected intravenously after 60 hours, 

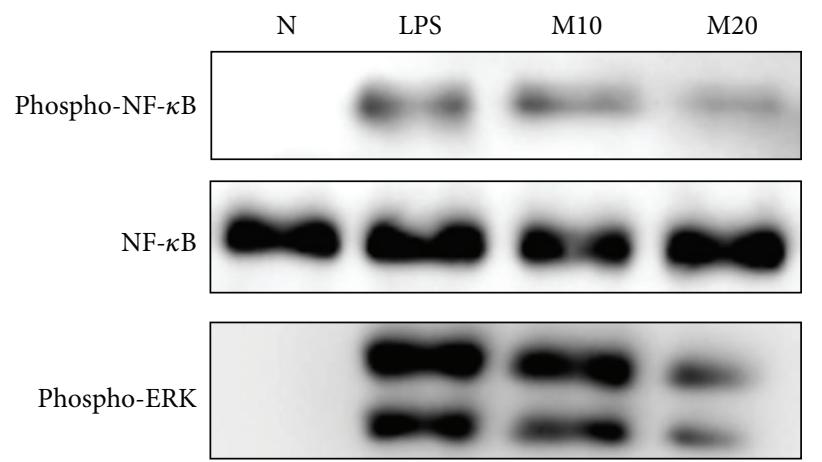

ERK

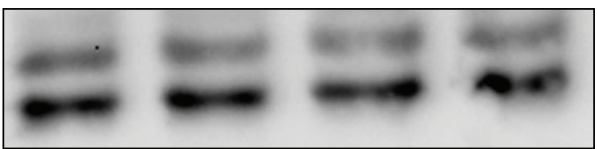

Phospho-p38

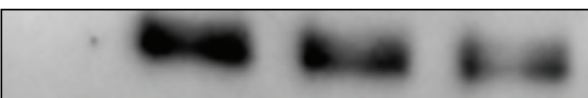

p38
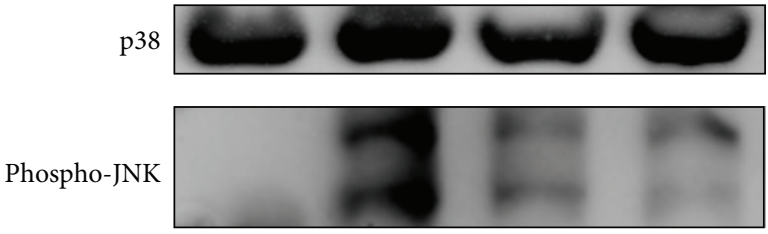

JNK
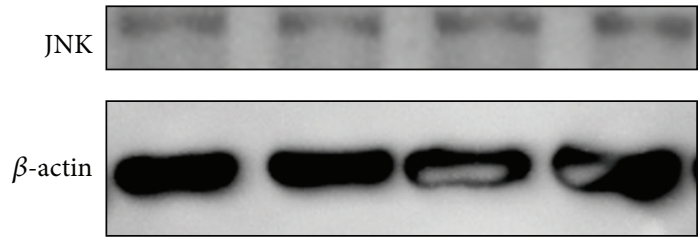

FIGURE 8: Matrine affects the LPS-induced nuclear phosphorylation of NF- $\kappa$ B and phosphorylation of MAPK pathway molecules. Phosphorylation in lung tissue was analyzed by Western blots. Three independent experiments were analyzed and results were compared with the LPS-treated group.

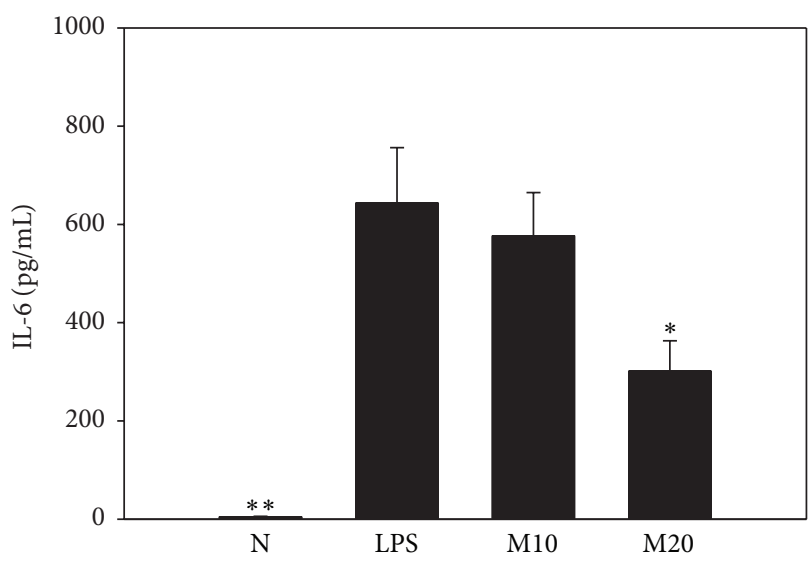

(a)

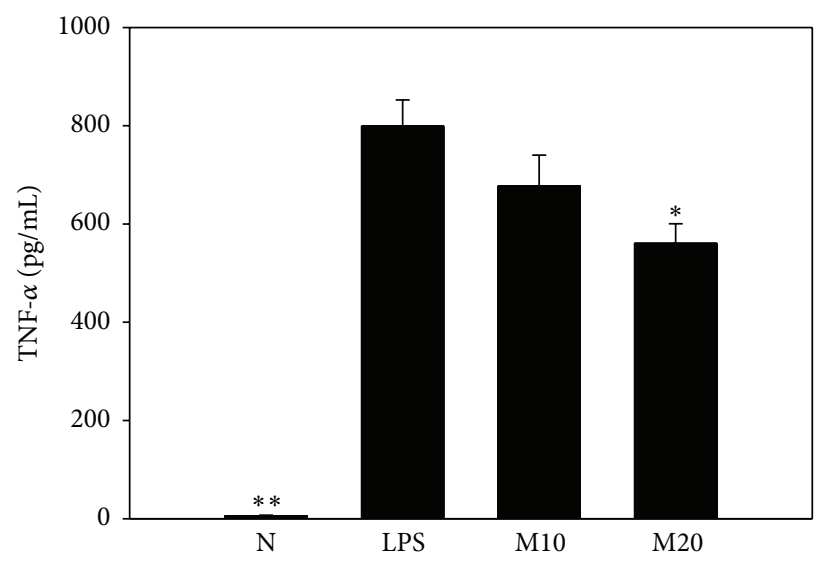

(b)

FIGURE 9: Matrine affects the serum levels of inflammatory cytokines, including IL-6 (a) and TNF- $\alpha$ (b). All data are presented as means \pm SEM. ${ }^{*} P<0.05$ compared with the LPS control group. 
and the survival rate was only $20 \%$. Mice given $20 \mathrm{mg} / \mathrm{kg}$ matrine did not show an increased survival rate; mice given $100 \mathrm{mg} / \mathrm{kg}$ matrine showed a 60\% survival rate and decreased lung damage [20]. In contrast, our present experimental model of lung injury involved intratracheal LPS injection to induce local inflammatory lung injury, which seems to be more suitable for assessing the inflammatory response. Furthermore, our experiment mainly investigated whether matrine could provide protection against lung injury in mice. The mice were treated with intraperitoneal matrine injection for continuous 7 days, followed by intratracheal LPS injection on the 8th day, and the mice were sacrificed four hours later. The experimental process did not lead to the death of any mice, and our model is more appropriate for observing the early response of acute lung injury and for evaluating the protective effects of matrine in early lung injury. Our results showed that $20 \mathrm{mg} / \mathrm{kg}$ matrine could protect and prevent lung injury symptoms in this experimental model. Despite the differences between our animal experimental model and the lung injury mouse model used by Zhang et al. [20], both sets of experimental results suggest that matrine can reduce lung injury in mice.

In cases of bacterial infection, neutrophils in the lung can ingest invading bacteria and release large amounts of inflammatory mediators to induce an inflammatory response in the lung [25]. Our experiments showed that treatment with $20 \mathrm{mg} / \mathrm{kg}$ of matrine suppressed neutrophil infiltration in the lung and correspondingly reduced the number of neutrophils in BALF. Chemokines-particularly IL-8, MCP1, and CCL5-induce neutrophil migration into inflammatory tissue [26]. Matrine inhibited the productions of IL8, MCP-1, and CCL5 in LPS-stimulated A549 cells and suppressed MCP-1 and CCL5 gene expressions in mouse lung tissue. Inflammatory lung epithelial cells also express ICAM1 adhesion molecules to promote neutrophil adsorption [18, 27]. Our experiments found that matrine suppressed ICAM1 expression both in vitro and in vivo. Overall, our results suggest that matrine may be useful for reducing neutrophil infiltration in the inflammatory response of the lungs. This would be particularly useful, since lung inflammation and lung damage in LPS-induced acute lung injury are mainly caused by neutrophil infiltration. On the other hand, matrine did not effectively reduce the gene expressions of CCL11 and CCL24 in the lung and, therefore, matrine did not improve eosinophilic infiltration in this LPS-induced lung injury mouse model. Matrine also did not effectively suppress the gene expressions of the Th2-associated cytokines IL-4 and IL-13 in lung tissue.

\section{Conclusion}

In conclusion, our results demonstrate that matrine significantly suppressed the inflammatory response in human lung epithelial cells and blocked ICAM-1 expression, preventing acute lung injury in LPS-induced mice.

\section{Conflict of Interests}

The authors declare that there is no conflict of interests regarding the publication of this paper.

\section{Authors' Contribution}

Chian-Jiun Liou and You-Rong Lai contributed equally to the paper.

\section{Acknowledgments}

This study was supported in part by grants from the Chang Gung Memorial Hospital (CMRPF1C0202 and CMRPF3E0051) and from the Chang Gung University of Science and Technology (EZRPF3E0191).

\section{References}

[1] C.-L. Tsai, Y.-C. Lin, H.-M. Wang, and T.-C. Chou, "Baicalein, an active component of Scutellaria baicalensis, protects against lipopolysaccharide-induced acute lung injury in rats," Journal of Ethnopharmacology, vol. 153, no. 1, pp. 197-206, 2014.

[2] Y. Aschner, R. L. Zemans, C. M. Yamashita, and G. P. Downey, "Matrix metalloproteinases and protein tyrosine Kinases: potential novel targets in acute lung injury and ARDS," Chest, vol. 146, no. 4, pp. 1081-1091, 2014.

[3] L. Xu, J. Xu, and Z. Wang, "Molecular mechanisms of paraquatinduced acute lung injury: a current review," Drug and Chemical Toxicology, vol. 37, no. 2, pp. 130-134, 2014.

[4] X. X. Liu, D. D. Yu, M. J. Chen et al., "Hesperidin ameliorates lipopolysaccharide-induced acute lung injury in mice by inhibiting HMGB1 release," International Immunopharmacology, vol. 25, no. 2, pp. 370-376, 2015.

[5] M. A. Taddonio, V. Dolgachev, M. Bosmann et al., "Influence of lipopolysaccharide-binding protein on pulmonary inflammation in gram-negative pneumonia," Shock, vol. 43, no. 6, pp. 612619, 2015.

[6] T. Yokochi, "A new experimental murine model for lipopolysaccharide-mediated lethal shock with lung injury," Innate Immunity, vol. 18, no. 2, pp. 364-370, 2012.

[7] H. Ma, J. Shi, C. Wang et al., "Blockade of PDE4B limits lung vascular permeability and lung inflammation in LPS-induced acute lung injury," Biochemical and Biophysical Research Communications, vol. 450, no. 4, pp. 1560-1567, 2014.

[8] B. V. Patel, M. R. Wilson, K. P. O’Dea, and M. Takata, “TNFinduced death signaling triggers alveolar epithelial dysfunction in acute lung injury," Journal of Immunology, vol. 190, no. 8, pp. 4274-4282, 2013.

[9] H. Li, G. Tan, X. Jiang et al., "Therapeutic effects of matrine on primary and metastatic breast cancer," American Journal of Chinese Medicine, vol. 38, no. 6, pp. 1115-1130, 2010.

[10] M. Sun, H. Cao, L. Sun et al., "Antitumor activities of kushen: literature review," Evidence-Based Complementary and Alternative Medicine, vol. 2012, Article ID 373219, 11 pages, 2012.

[11] J.-P. Zhang, M. Zhang, C. Jin et al., "Matrine inhibits production and actions of fibrogenic cytokines released by mouse peritoneal macrophages," Acta Pharmacologica Sinica, vol. 22, no. 8, pp. 765-768, 2001.

[12] W.-C. Huang, C.-C. Chan, S.-J. Wu et al., "Matrine attenuates allergic airway inflammation and eosinophil infiltration by suppressing eotaxin and Th2 cytokine production in asthmatic mice," Journal of Ethnopharmacology, vol. 151, no. 1, pp. 470-477, 2014. 
[13] W.-T. Chang, W.-C. Huang, and C.-J. Liou, "Evaluation of the anti-inflammatory effects of phloretin and phlorizin in lipopolysaccharide-stimulated mouse macrophages," Food Chemistry, vol. 134, no. 2, pp. 972-979, 2012.

[14] W.-C. Huang and C.-J. Liou, "Dietary acacetin reduces airway hyperresponsiveness and eosinophil infiltration by modulating eotaxin-1 and Th2 cytokines in a mouse model of asthma," Evidence-Based Complementary and Alternative Medicine, vol. 2012, Article ID 910520, 11 pages, 2012.

[15] Y.-L. Liu, Y.-J. Liu, Y. Liu et al., "Hydroxysafflor yellow A ameliorates lipopolysaccharide-induced acute lung injury in mice via modulating toll-like receptor 4 signaling pathways," International Immunopharmacology, vol. 23, no. 2, pp. 649-657, 2014.

[16] C.-J. Liou and W.-C. Huang, "Dehydroepiandrosterone suppresses eosinophil infiltration and airway hyperresponsiveness via modulation of chemokines and Th2 cytokines in ovalbuminsensitized mice," Journal of Clinical Immunology, vol. 31, no. 4, pp. 656-665, 2011.

[17] C. Lawson and S. Wolf, "ICAM-1 signaling in endothelial cells," Pharmacological Reports, vol. 61, no. 1, pp. 22-32, 2009.

[18] W. C. Huang, S. J. Wu, R. S. Tu, Y. R. Lai, and C. J. Liou, "Phloretin inhibits interleukin- $\beta$-induced COX-2 and ICAM-1 expression through inhibition of MAPK, Akt, and NF- $\kappa$ B signaling in human lung epithelial cells," Food \& Function, vol. 6, no. 6, pp. 1960-1967, 2015.

[19] Z.-J. Ma, Q. Li, J.-B. Wang et al., "Combining oxymatrine or matrine with lamivudine increased its antireplication effect against the hepatitis B virus in vitro," Evidence-Based Complementary and Alternative Medicine, vol. 2013, Article ID 186573, 8 pages, 2013.

[20] B. Zhang, Z.-Y. Liu, Y.-Y. Li et al., "Antiinflammatory effects of matrine in LPS-induced acute lung injury in mice," European Journal of Pharmaceutical Sciences, vol. 44, no. 5, pp. 573-579, 2011.

[21] F. Peri, M. Piazza, V. Calabrese, G. Damore, and R. Cighetti, "Exploring the LPS/TLR4 signal pathway with small molecules," Biochemical Society Transactions, vol. 38, no. 5, pp. 1390-1395, 2010.

[22] M. R. Karta, M. L. Gavala, C. S. Curran et al., "LPS modulates rhinovirus-induced chemokine secretion in monocytes and macrophages," American Journal of Respiratory Cell and Molecular Biology, vol. 51, no. 1, pp. 125-134, 2014.

[23] K. Hostanska, J. Melzer, A. Amon, and R. Saller, "Suppression of interleukin (IL)-8 and human beta defensin-2 secretion in LPSand/or IL-1 $\beta$-stimulated airway epithelial A549 cells by a herbal formulation against respiratory infections (BNO 1030)," Journal of Ethnopharmacology, vol. 134, no. 2, pp. 228-233, 2011.

[24] J. M. Kyriakis and J. Avruch, "Mammalian MAPK signal transduction pathways activated by stress and inflammation: a 10-year update," Physiological Reviews, vol. 92, no. 2, pp. 689737, 2012.

[25] S. L. Poe, M. Arora, T. B. Oriss et al., "STAT1-regulated lung MDSC-like cells produce IL-10 and efferocytose apoptotic neutrophils with relevance in resolution of bacterial pneumonia," Mucosal Immunology, vol. 6, no. 1, pp. 189-199, 2013.

[26] M. D. Turner, B. Nedjai, T. Hurst, and D. J. Pennington, "Cytokines and chemokines: at the crossroads of cell signalling and inflammatory disease," Biochimica et Biophysica Acta
(BBA)-Molecular Cell Research, vol. 1843, no. 11, pp. 25632582, 2014.

[27] Y. Tao, Y.-C. Chen, T. Lan, H. Qian, Y. Wang, and L. Jiang, "LPSinduced nuclear translocation of RhoA is dependent on NF- $\kappa \mathrm{B}$ in the human lung cancer cell line A549," Oncology Letters, vol. 3, no. 6, pp. 1283-1287, 2012. 


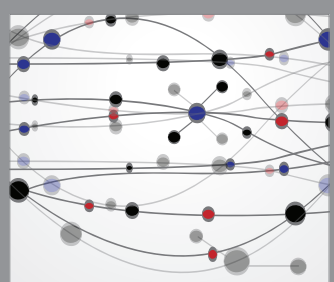

The Scientific World Journal
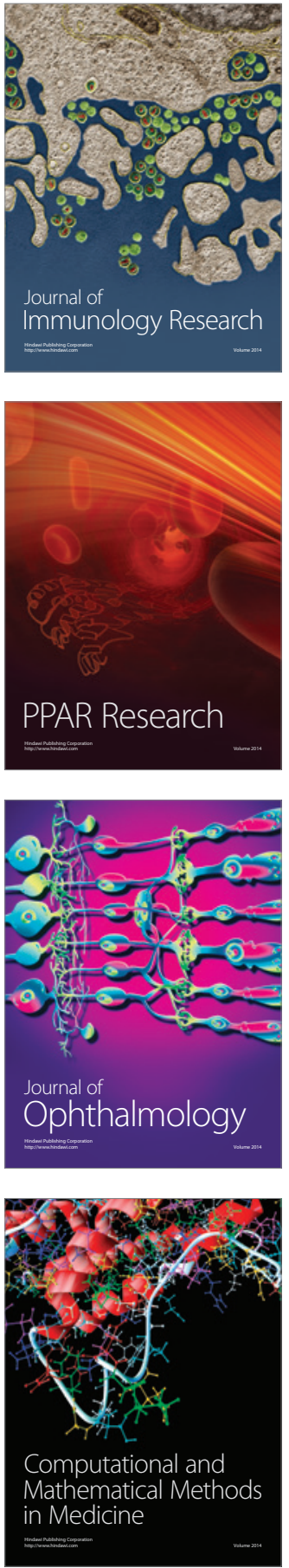

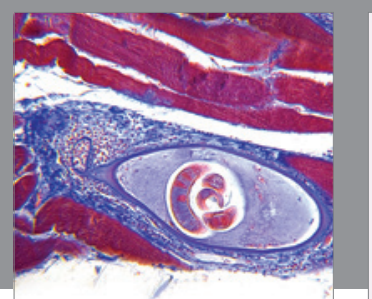

Gastroenterology Research and Practice

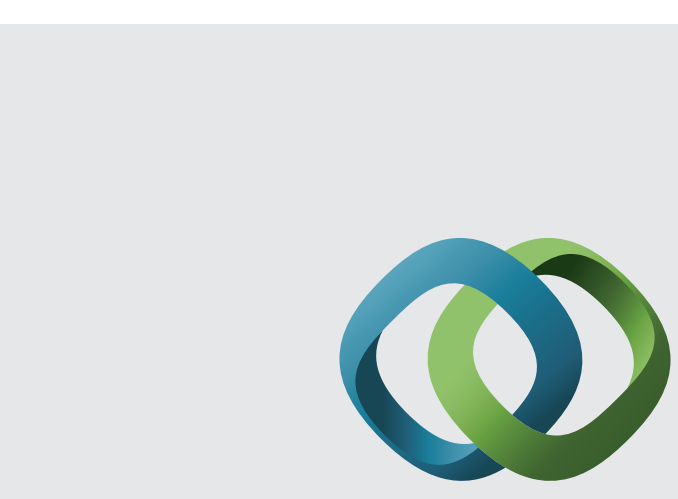

\section{Hindawi}

Submit your manuscripts at

http://www.hindawi.com
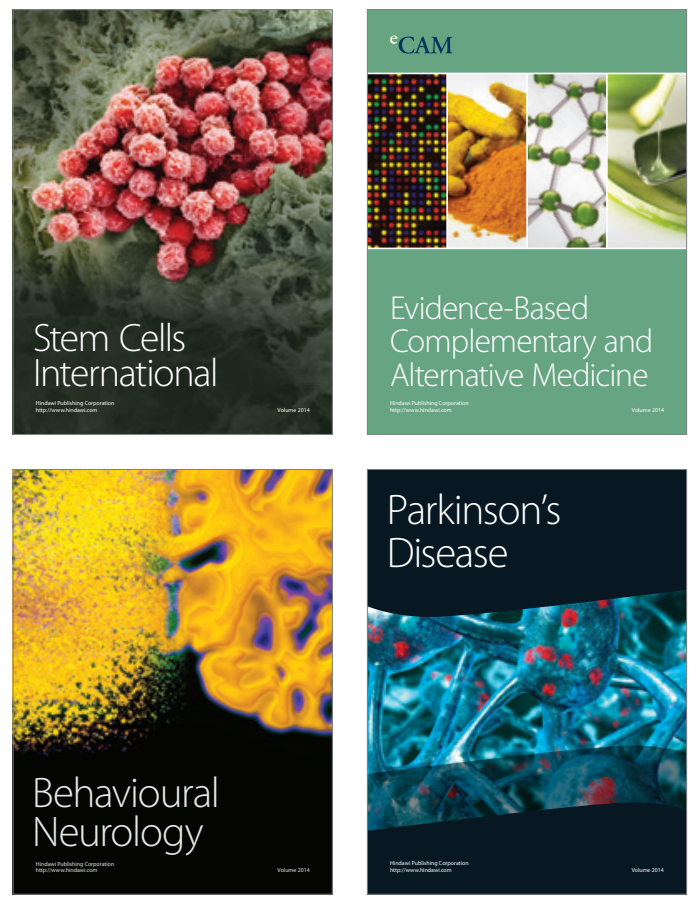
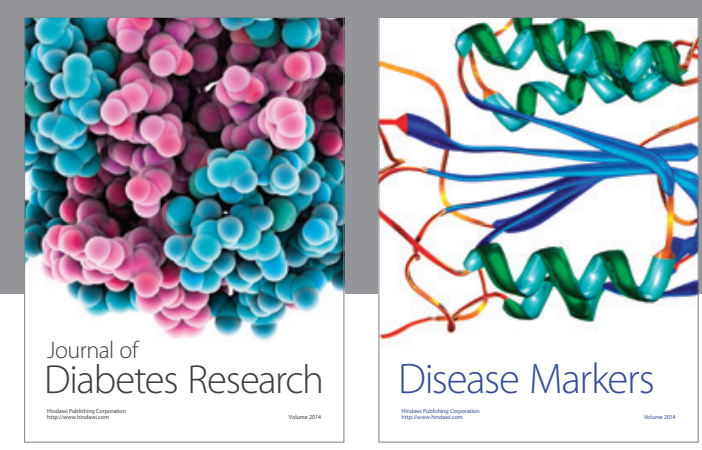

Disease Markers
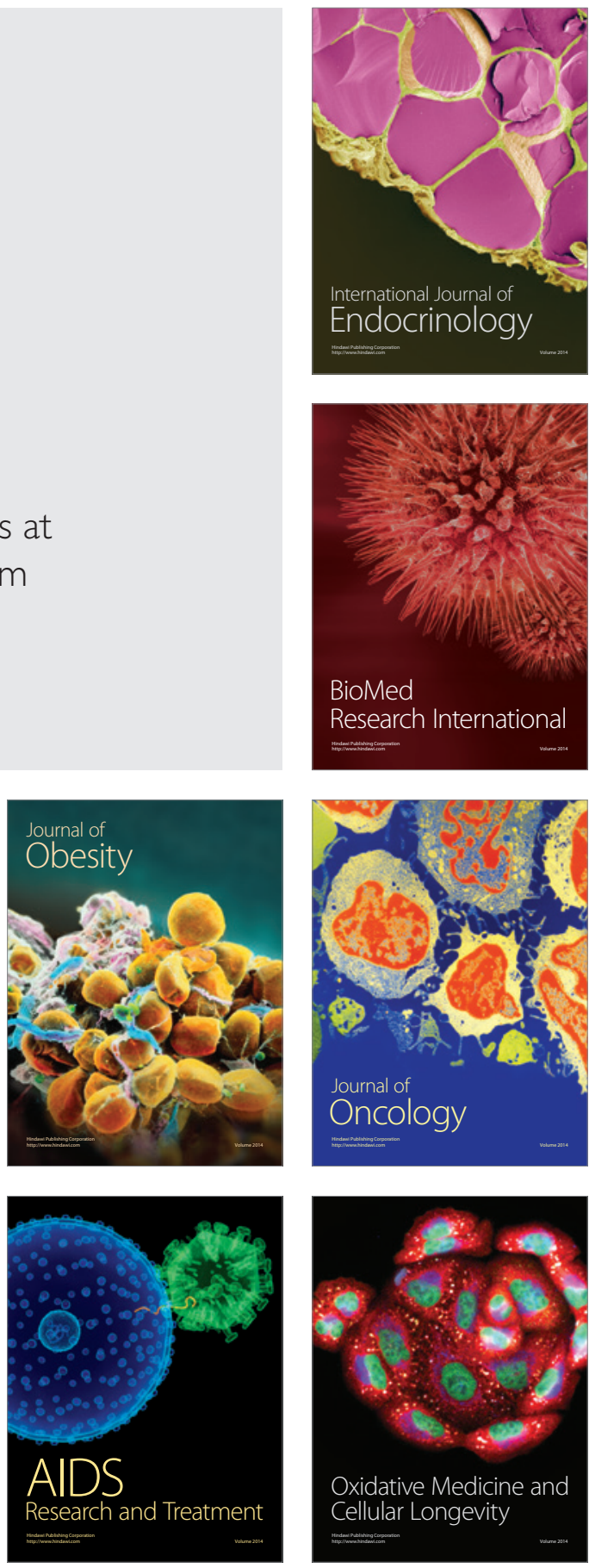